\title{
Single-dose fentanyl sublingual spray for breakthrough cancer pain
}

This article was published in the following Dove Press journal:

Clinical Pharmacology:Advances and Applications

23 July 2013

Number of times this article has been viewed

\section{Donald R Taylor}

Comprehensive Pain Care PC, Marietta, GA, USA
Correspondence: Donald R Taylor Comprehensive Pain Care PC, 840 Church Street, Suite D, Marietta, GA 30060, USA

$\mathrm{Tel}+\mathrm{I} 7704218080$

Fax +I 7704219566

Email dtaylor@cpcnopain.com
Abstract: Breakthrough cancer pain (BTCP) is defined as a transient exacerbation of pain that arises in patients with otherwise controlled persistent pain. BTCP typically has a rapid onset and relatively short duration, but it causes a significant amount of physical and psychological distress for patients. Several rapid-onset fentanyl formulations have been introduced in the USA to replace traditional oral opioids for the treatment of BTCP: a transmucosal lozenge, a sublingual orally disintegrating tablet, a buccal tablet, a buccal soluble film, a pectin nasal spray and, the newest formulation to enter the market, a sublingual spray. This article reviews the six rapid-onset formulations of fentanyl approved in the USA for the management of BTCP with emphasis on describing the published literature on fentanyl sublingual spray. The different fentanyl formulations vary in pharmacokinetic properties and ease of use, but all have a rapid onset and a relatively short duration of analgesia. Fentanyl sublingual spray has demonstrated absorption within 5 minutes of administration, with fentanyl plasma concentrations increasing over the first 30 minutes and remaining elevated for 60-90 minutes in pharmacokinetic studies in healthy subjects. Fentanyl sublingual spray shows linear dose proportionality, and changes in the temperature or acidity of the oral cavity do not alter its pharmacokinetic properties. In patients with BTCP, statistically significant pain relief is measurable at 5 minutes after administration of fentanyl sublingual spray, when compared with placebo, with significant pain relief lasting at least 60 minutes after administration. Adverse events are typical of opioid treatment and are considered mild to moderate in intensity. In summary, fentanyl sublingual spray provides rapid onset of analgesia and is a tolerable and effective treatment for BTCP.

Keywords: breakthrough pain, cancer, fentanyl, rapid-onset opioid, sublingual, fentanyl sublingual spray

\section{Introduction}

Moderate to severe pain is common among patients with cancer and remains a significant challenge to practitioners, despite advances in pain management and the widespread adoption of the World Health Organization (WHO) guidelines for cancer pain management. ${ }^{1,2}$ The WHO 3-step "ladder" approach to cancer treatment includes the use of opioids with fixed, around-the-clock dosing in patients who do not respond to non-opioid analgesics. ${ }^{3,4}$ However, breakthrough cancer pain (BTCP) is a common problem that is currently only minimally addressed by the WHO pain relief ladder. ${ }^{1,3}$

BTCP has been defined as "a transitory exacerbation of pain that occurs on a background of otherwise stable pain in a patient receiving chronic opioid therapy." It is distinguished from continuous background pain that is relatively well managed with opioids. BTCP episodes are generally moderate to severe in intensity, reach 
peak intensity in approximately 3 minutes, and generally last $\leq 30$ minutes. ${ }^{5-7}$

Estimates of the incidence and prevalence of BTCP vary, although BTCP is more common among patients with advanced disease. ${ }^{5}$ Results of a survey of adult inpatients referred for evaluation and treatment to a cancer pain management service showed that of 63 patients who achieved stable opioid dosing and reported pain of moderate or less intensity, 41 (65\%) experienced at least one episode of BTCP in the preceding 24 hours, with a median of four episodes. ${ }^{5} \mathrm{Of}$ 51 episodes of BTCP, the maximum intensity occurred within 3 minutes of onset in $22(43 \%)$ episodes, and the median duration was 30 minutes. ${ }^{5}$ Another study of 245 patients admitted for hospice care showed that 218 patients (89\%) experienced BTCP, with approximately $88 \%$ of those patients experiencing more than one episode per day and $84 \%$ of episodes producing moderate, severe, or excruciating pain. The majority ( $73 \%$ ) of BTCP episodes lasted $\leq 30$ minutes, with $26 \%$ lasting just 10 minutes or less. ${ }^{7}$

BTCP is associated with a high level of patient dissatisfaction with treatment and also has a negative impact on patients' lives. ${ }^{6-8}$ Impairments in sleep, concentration, emotional well-being, interpersonal relationships, everyday function, and work performance are common in patients with BTCP. ${ }^{6,89}$ For example, for some patients, the simple act of turning in bed can trigger an episode of BTCP and thereby interfere with sleep. ${ }^{9}$ For other patients, even gentle hugs can bring on excruciating BTCP, thus preventing physical contact with others and straining personal relationships. ${ }^{8}$

This review will focus on current management strategies for BTCP, with a focus on the newest formulation of rapidonset fentanyl: namely, fentanyl sublingual spray.

\section{Opioids for the management of BTCP}

Although traditional oral opioids, such as morphine, have been the mainstay in the treatment of BTCP, their effectiveness is limited by a relatively slow onset of analgesia (often $\geq 30$ minutes), the need for hepatic first-pass metabolism (which reduces bioavailability), the relatively long duration of effect (which increases the risk for adverse events), and variable absorption. ${ }^{10-13}$ Oral opioids also are not ideal in patients with nausea, vomiting, or dysphagia. ${ }^{11,14,15}$

Several rapid-onset formulations of fentanyl have been approved by the US Food and Drug Administration (FDA) for the treatment of BTCP. Fentanyl is a synthetic, highly potent, lipophilic $\mu$-opioid agonist that rapidly crosses the blood-brain barrier and has a half-life ranging from
1.6 to 6 hours. ${ }^{13,16}$ The different fentanyl formulations vary in pharmacokinetic properties and ease of use, but all of them have a rapid onset and a relatively short duration of analgesia. ${ }^{10,17}$ In comparison with traditional oral opioids, the rapid-onset fentanyl formulations convey a significant advantage in the treatment of BTCP, with a pharmacokinetic profile that more closely matches that of a BTCP episode. . $^{10,13,17,18}$ With the approval of fentanyl sublingual spray by the FDA in January $2012,{ }^{19}$ six rapid-onset formulations of fentanyl are now available in the USA - transmucosal lozenge, sublingual orally disintegrating tablet, buccal tablet, buccal soluble film, pectin nasal spray, and sublingual spray (Table 1). ${ }^{13,17,20-29}$

Randomized, double-blind, placebo-controlled clinical trials in adults with cancer have demonstrated the efficacy of each of these rapid-onset fentanyl formulations in the treatment of BTCP. ${ }^{10,18,26,27,29-31}$ Adverse events in these trials have been typical for opioids (the most common being nausea, vomiting, headache, dizziness, and somnolence). . $8,26,27,29-31^{2}$

Although all of the rapid-onset fentanyl formulations show efficacy in the treatment of BTCP in opioid-tolerant patients, each formulation has certain advantages and disadvantages. The oral transmucosal fentanyl citrate (OTFC) lozenge requires effort on the part of the patient to control the administration, which results in variability in absorption and the swallowing of a significant amount of drug. 13,17,26,27 Any fentanyl swallowed in saliva will undergo hepatic firstpass metabolism, resulting in reduced bioavailability. ${ }^{13,14}$ In addition, one OTFC unit contains 2 grams of sugar, and prolonged use may increase the risk of dental decay, including dental caries..$^{20,32}$ Fentanyl buccal tablets have greater bioavailability than OTFC (65\% versus 50\%), but the tablets

Table I Comparison of available rapid-onset fentanyl formulations

\begin{tabular}{llll}
\hline Product & Formulation & $\begin{array}{l}\text { Site of } \\
\text { absorption }\end{array}$ & $\begin{array}{l}\text { Onset of } \\
\text { analgesia* }\end{array}$ \\
\hline $\begin{array}{l}\text { Oral transmucosal } \\
\text { fentanyl citrate }{ }^{13,20,30}\end{array}$ & Lozenge & Buccal mucosa & 15 minutes \\
$\begin{array}{l}\text { Fentanyl citrate } \\
\text { sublingual tablet }\end{array}$ & $\begin{array}{l}\text { Orally } \\
\text { disintegrating } \\
\text { tablet }\end{array}$ & $\begin{array}{l}\text { Sublingual } \\
\text { mucosa }\end{array}$ & 10 minutes \\
$\begin{array}{l}\text { Fentanyl citrate } \\
\text { buccal tablet }\end{array}$ & Tablet & Buccal mucosa & 15 minutes \\
$\begin{array}{l}\text { Fentanyl citrate buccal } \\
\text { soluble film }\end{array}$ & Soluble film & Buccal mucosa & 30 minutes \\
$\begin{array}{l}\text { Fentanyl pectin nasal } \\
\text { spray }{ }^{13,24,28}\end{array}$ & Intranasal spray & Nasal mucosa & 10 minutes \\
$\begin{array}{l}\text { Fentanyl sublingual } \\
\text { spray }\end{array}$ & Sublingual spray & $\begin{array}{l}\text { Sublingual } \\
\text { mucosa }\end{array}$ & 5 minutes \\
\hline
\end{tabular}

Note: *Onset of analgesia was defined as the earliest time point at which a statistically significant difference in the pain intensity difference score was measured. 
still require 14 to 25 minutes to disintegrate completely, and approximately $50 \%$ is swallowed in the saliva. ${ }^{20,22}$ Fentanyl sublingual orally disintegrating tablet disintegrates rapidly and has an overall bioavailability of $54 \% .^{10,21}$ The tablet must remain under the tongue, and patients should avoid swallowing during administration. ${ }^{21}$ Fentanyl buccal soluble film requires little effort on the part of the patient; little saliva is necessary for absorption, but the film requires up to 30 minutes to completely dissolve and $49 \%$ of the dose is swallowed with saliva. ${ }^{10,13,23,27}$ Fentanyl pectin nasal spray may be useful in patients with nausea and vomiting, whereby oral administration is difficult; ${ }^{13,33}$ however, some patients are less accepting of intranasal administration, and coexisting nasal problems may complicate use..$^{14,34,35}$ Fentanyl sublingual spray requires minimal patient effort, and little drug is swallowed in saliva. ${ }^{14,29,36}$ In a clinical trial, patients indicated that the sublingual spray formulation is convenient and easy to use. ${ }^{29}$ Fentanyl sublingual spray provides a useful alternative to fentanyl intranasal spray for patients with nasal problems or those who dislike the intranasal route of administration, although it should be used with caution in patients with grade $\geq 2$ mucositis unless the benefits outweigh the potential risk from possible increased exposure. ${ }^{25}$

Several cancer treatment guidelines discuss options for the management of BTCP that include the use of rapid-onset opioids. The National Comprehensive Cancer Network recommends rapid-onset opioids when exacerbations of pain are not due to inadequate around-the-clock dosing. ${ }^{37}$ The European Society for Medical Oncology recommends use of opioids with a rapid onset and short duration of action. ${ }^{38}$ The European Association for Palliative Care recommends oral immediate-release opioids or transmucosal fentanyl and acknowledges that the latter are preferable in some cases due to their rapid onset and shorter duration of effect. ${ }^{39}$

Although each of these guidelines mentions BTCP, none explicitly addresses it. The Science Committee of the Association for Palliative Medicine of Great Britain and Ireland recently formulated guidelines specifically for the treatment for BTCP, although the Committee notes that their recommendations are based on limited evidence and provide only general strategies. ${ }^{40}$ Nonetheless, their recommendations include the use of opioids as first-line pharmacologic treatment for BTCP, noting that oral immediate-release opioids are not optimal due to their delayed onset and long duration of analgesia and rapid-onset opioid formulations, such as transmucosal (sublingual, buccal, intranasal, pulmonary) formulations, may be more advantageous. ${ }^{40}$ Clearly, there is a need for new clinical trials on the treatment of BTCP and the development of definitive, evidence-based, treatment guidelines.

BTCP treatment options need to optimize the benefits while minimizing the risks for any particular patient. As with all potent opioids, there is a risk of abuse, addiction, and diversion with fentanyl products. There is little literature on abuse and misuse of the rapid-onset formulations of fentanyl used to treat BTCP, although rates for abuse and addiction to rapid-onset fentanyl that have been reported in longer-term clinical trials of patients with chronic noncancer pain are low. ${ }^{16,41-43}$ However, abuse and misuse of rapid-onset fentanyl should not be overlooked when treating patients with cancerrelated pain. Medical professionals need to consider the challenge of managing cancer pain or pain among survivors over a potentially longer duration, as cancer is no longer considered a terminal disease. Advancements in medical therapy have helped patients with cancer live longer, and survival rates have increased. ${ }^{44}$ All patients treated with opioids require careful monitoring of signs of misuse. Diversion is an important consideration among patients receiving palliative care in nursing facilities or from caregivers at home. ${ }^{42,45}$

In an attempt to mitigate the risk of misuse, abuse, addiction, overdose, and serious complications due to medication errors associated with use of opioids, the FDA has instituted a Risk Evaluation and Mitigation Strategy (REMS) for the class of transmucosal immediate-release fentanyl products. ${ }^{46}$ A similar class-wide REMS has been implemented for all of the extended-release and long-acting opioids used to treat chronic pain. ${ }^{47}$ These REMS programs were designed to educate prescribers and pharmacists on appropriate patient selection and on providing patients with information on the proper use, storage, and disposal of potent opioids to minimize risks and improve patient outcomes. ${ }^{46,47}$

\section{Fentanyl sublingual spray for BTCP}

Fentanyl sublingual spray (Subsys ${ }^{\circledR}$, INSYS Therapeutics, Inc, Chandler, AZ, USA) was approved by the FDA in 2012 for the treatment of BTCP in adult patients who are already receiving and who are tolerant to opioids for the management of underlying persistent cancer pain. ${ }^{13,19,25}$ Fentanyl sublingual spray is available in dosages of 100, 200, 400, 600, 800, 1200, and $1600 \mu \mathrm{g} .{ }^{25}$ The $1200 \mu \mathrm{g}$ dose is provided as packages of two $600 \mu \mathrm{g}$ units, and the $1600 \mu \mathrm{g}$ dose is provided as packages of two $800 \mu \mathrm{g}$ units.

The sublingual route of administration offers several advantages over other routes of administration. First, the sublingual mucosa is highly vascularized and is the most permeable region of the oral mucosa. It contains a relatively 
large surface area with a mucosal thickness measuring about $100-200 \mu \mathrm{m}$, compared with $500-800 \mu \mathrm{m}$ for the buccal mucosa. ${ }^{48,49}$ Sublingual administration also bypasses hepatic first-pass metabolism, which minimizes variability in bioavailability. ${ }^{14,15,48}$ The sublingual route of administration is particularly useful in patients with nausea, vomiting, or dysphagia. ${ }^{15}$ In terms of patient preference, there is some indication that patients prefer the sublingual route of administration over other routes of administration, such as intranasal or rectal, for treatment of BTCP. ${ }^{34}$ In comparison with most other opioids, fentanyl has a significantly greater degree of sublingual absorption, ${ }^{15}$ with fewer adverse effects such as unpleasant taste, burning, light-headedness, and numbness. ${ }^{15}$

Fentanyl sublingual spray may produce a rapid onset of analgesia in part because the liquid formulation bypasses the need for tablet disintegration and allows for distribution of the active compound throughout the sublingual mucosa, thereby potentially maximizing the rate and extent of absorption. ${ }^{29} \mathrm{In}$ addition, fentanyl sublingual spray is composed of the more permeable base form of fentanyl and contains menthol. ${ }^{25,50,51}$ The non-ionized base form of fentanyl favors lipophilicity and absorption through the sublingual membrane, which increases bioavailability. ${ }^{50,51}$ In fact, the base form of fentanyl has demonstrated $\geq 30 \%$ bioavailability compared with the fentanyl citrate salt formulation. ${ }^{50}$ Menthol has long been recognized as a highly effective permeation enhancer for a variety of compounds and tissues, including the transmucosal mucosa. ${ }^{52-54}$ Fentanyl sublingual spray has the unique advantage of combining base fentanyl with menthol to achieve fast absorption and superior bioavailability, with minimal variability. ${ }^{50,51}$

Published clinical trials of fentanyl sublingual spray have evaluated its pharmacokinetic properties in healthy subjects and determined its efficacy and tolerability in opioid-tolerant patients with BTCP. $29,36,55$

\section{Pharmacokinetics of fentanyl sublingual spray}

A two-part, Phase I, randomized, five-period crossover trial in healthy adults (aged 18-55 years) was conducted to determine the dose-proportionality of five doses of fentanyl sublingual spray $(100,200,400,600$, and $800 \mu \mathrm{g})$ under fasted conditions (Part A), and determine the effects of temperature and $\mathrm{pH}$ in the oral cavity on the bioavailability of fentanyl after administration of fentanyl sublingual spray $200 \mu \mathrm{g}$ (Part B). ${ }^{55} \mathrm{~A}$ total of 53 subjects ( 38 female, 15 male) were enrolled in Part A and 14 subjects ( 3 female, 11 male) were enrolled in Part B. Subjects withdrew due to positive urine drug screen $(n=2)$, positive urine alcohol screen $(n=1)$, and withdrawal of consent $(n=9)$. The mean \pm standard deviation (SD) age of subjects was $31 \pm 10$ years in Part A and $32 \pm 10$ years in Part B. ${ }^{55}$

Mean 36-hour plasma fentanyl concentrations across five different doses are shown in Figure $1 .{ }^{55}$ For all doses of fentanyl sublingual spray, mean plasma concentration of fentanyl was detectable within 5 minutes, the first sample point, and was approximately $27.3 \%, 60.6 \%$, and $86.6 \%$ of the mean maximum plasma concentration $\left(\mathrm{C}_{\max }\right)$ within 5,10 , and 20 minutes of administration, respectively. Mean plasma concentration of fentanyl reached a plateau approximately 30 minutes after administration, which was maintained for 60-90 minutes. ${ }^{55}$ Mean $\mathrm{C}_{\max }$ increased and median time to maximum plasma concentration $\left(\mathrm{T}_{\max }\right)$ decreased with increasing doses of fentanyl sublingual spray. Linear dose proportionality was demonstrated across the dose range of $100-800 \mu \mathrm{g}$ of fentanyl sublingual spray, as determined by linear regression of $\mathrm{C}_{\max }$ and area under the concentrationtime curve (AUC) from time zero extrapolated to infinity $\left(\mathrm{AUC}_{\infty}\right.$ ) (Figure 2). Pretreatment of the oral cavity with a cold or hot beverage or a low- or high-pH beverage did not alter the absorption of fentanyl sublingual spray significantly, as determined by assessing $\mathrm{C}_{\max }$ and $\mathrm{AUC}_{\infty}$ under different temperature and acidity conditions. ${ }^{55}$

Fentanyl sublingual spray was generally well tolerated. Treatment-emergent adverse events were reported by 31 of 53 subjects (58.5\%) in Part A and 9 of 14 subjects (64.3\%) in Part B. ${ }^{55}$ The most commonly reported adverse events were nausea ( $n=17)$, vomiting/intermittent vomiting $(n=12)$, and somnolence $(\mathrm{n}=8)$ in Part A and nausea $(\mathrm{n}=10)$, vomiting $(n=3)$, and headache $(n=3)$ in Part B. ${ }^{55}$

A second pharmacokinetic study was conducted as a single-dose, randomized, open-label, three-way crossover trial in healthy adults (aged 18-55 years) to compare the rate of absorption and systemic bioavailability of fentanyl sublingual spray $400 \mu \mathrm{g}$ with OTFC lozenge $400 \mu \mathrm{g} .{ }^{36}$ Intravenous fentanyl citrate $100 \mu \mathrm{g}$ was used as an independent treatment, and a $\geq 7$-day washout period separated treatments. Of 40 enrolled subjects (eight female, 32 male), 29 completed all three treatment periods. Reasons for withdrawal were noncompliance $(n=8)$, violation of entry criteria $(n=2)$, and withdrawn consent $(n=1)$. The mean \pm SD age of subjects who completed the study was $35 \pm 10$ years. ${ }^{36}$

Compared with OTFC, fentanyl sublingual spray was associated with a higher $\mathrm{C}_{\max }$ and greater mean fentanyl plasma concentration from 5 minutes through 6 hours after 


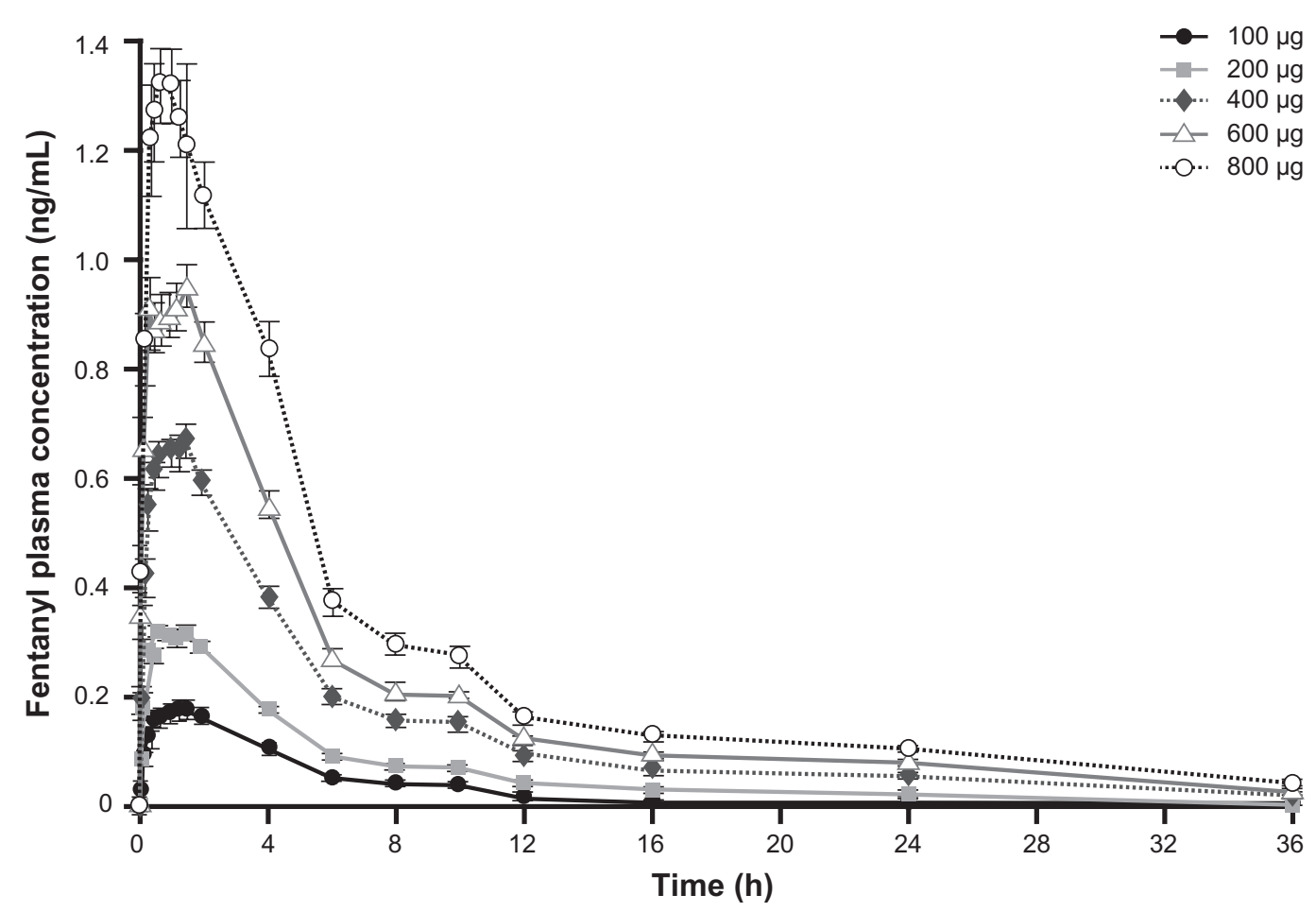

Figure I Mean \pm SE fentanyl plasma concentrations $(\mathrm{ng} / \mathrm{mL})$ over time (5 minutes to 36 hours) after a single administration of fentanyl sublingual spray at concentrations of $100,200,400,600$, or $800 \mu \mathrm{g}$ in healthy volunteers.

Notes: Reprinted with permission from Clin Drug Investig. 2013;33(6):391-400. Pharmacokinetics and dose proportionality of fentanyl sublingual spray: a single-dose 5-way crossover study. Parikh N, Goskonda V, Chavan A, Dillaha L. Copyright (C) 2013; with kind permission from Springer Science+Business Media B.V. ${ }^{55}$

Abbreviation: SE, standard error.

administration (Figure 3). ${ }^{36}$ In addition, $\mathrm{T}_{\max }$ was achieved more rapidly after dosing with fentanyl sublingual spray than with OTFC (median 1.5 hours versus 2.0 hours; $P<0.05$ ). Five minutes after administration, mean plasma concentration of fentanyl was $19.0 \%$ of $\mathrm{C}_{\max }$ for fentanyl sublingual spray and below the lower limit of quantification of the assay $(<0.025 \mathrm{ng} / \mathrm{mL}$ ) for OTFC (Figure 4). Ten minutes after administration, mean plasma concentration of fentanyl was $53.7 \%$ of $\mathrm{C}_{\max }$ with fentanyl sublingual spray and $6.1 \%$ of $\mathrm{C}_{\max }$ with OTFC (Figure 4). The systemic bioavailability, calculated using $\mathrm{AUC}_{\infty}$ or $\mathrm{AUC}$ from time zero to last quantifiable concentration $\left(\mathrm{AUC}_{\text {last }}\right)$, was $76 \%$ and $72 \%$, respectively, after fentanyl sublingual spray administration compared with $51 \%$ and $54 \%$, respectively, after OTFC administration. ${ }^{36}$

Both fentanyl sublingual spray and OTFC were well tolerated, with 15 of 40 subjects (37.5\%) reporting adverse events. ${ }^{36}$ Only five of 26 reported adverse events were considered to be probably or possibly related to treatment (two reports of glossodynia and one report each of dizziness, headache, and dry throat). ${ }^{36}$

Overall, the results of these studies demonstrate linear dose proportionality of fentanyl sublingual spray across the dose range of 100-800 $\mu \mathrm{g}$, indicating an increase in the rate of absorption and bioavailability of fentanyl with increasing doses. Fentanyl was detectable in the plasma within 5 minutes after administration, with a sustained elevation in fentanyl plasma concentration starting approximately 30 minutes after administration that was maintained for $60-90$ minutes. ${ }^{55}$ Alterations in the temperature and acidity of the oral cavity did not affect the pharmacokinetic properties of fentanyl sublingual spray and thus would not alter the effective dosage. Furthermore, fentanyl sublingual spray achieved greater mean plasma concentrations as early as 5 minutes after administration and had greater bioavailability ( $76 \%$ versus $51 \%$ ) than OTFC lozenge.

\section{Efficacy and tolerability of fentanyl sublingual spray}

A randomized, multicenter, double-blind, placebo-controlled clinical trial evaluated the efficacy and tolerability of and patient satisfaction with fentanyl sublingual spray in adult (aged $\geq 18$ years) patients with cancer who were receiving opioids for the treatment of cancer-related or treatment-related pain of moderate intensity or less, were opioid-tolerant, and experienced one to four episodes of BTCP daily. ${ }^{29} \mathrm{~A} \leq 26$-day open-label titration phase was 

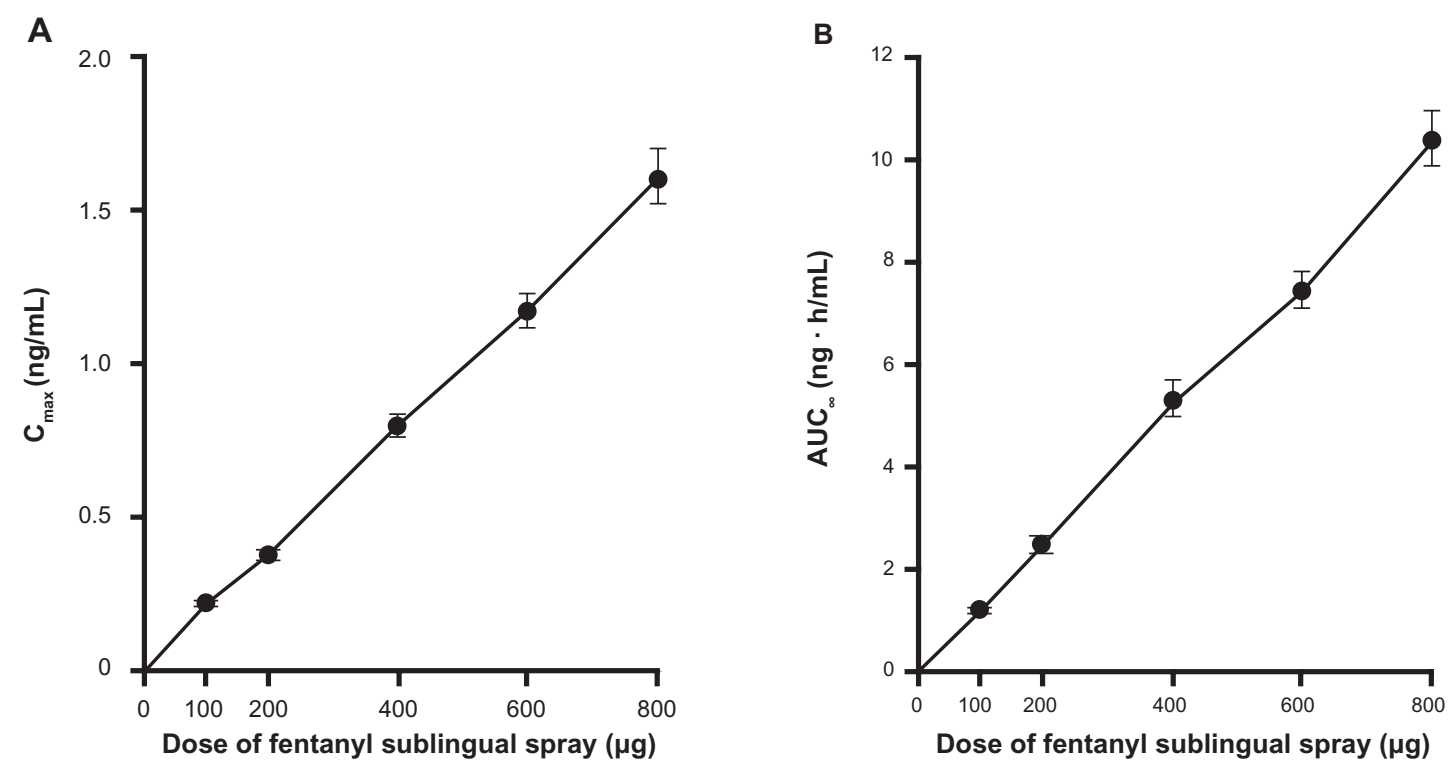

Figure 2 Relationship between mean fentanyl $C_{\max }(\mathbf{A})$ and $A \cup C_{\infty}(\mathbf{B})$ versus dose following administration of single doses of fentanyl sublingual spray $(\mathrm{I} 00-800 \mu \mathrm{g})$. Linear regression generated slopes \pm SE of $1.06 \pm 0.016$ for $C_{\max }$ and I.02 \pm 0.020 for $A U C_{\infty}$; both with coefficient of determination $\left(r^{2}\right)=0.999$, demonstrating dose proportional, linear pharmacokinetics. A slope of $\mathrm{I}$ indicates dose proportionality or linear pharmacokinetics.

Notes: Reprinted with permission from Clin Drug Investig. 2013;33(6):39I-400. Pharmacokinetics and dose proportionality of fentanyl sublingual spray: a single-dose 5-way crossover study. Parikh N, Goskonda V, Chavan A, Dillaha L. Copyright @ 2013 ; with kind permission from Springer Science+Business Media B.V. ${ }^{55}$

Abbreviations: $A \cup C_{\infty}$, area under the concentration-time curve from time zero extrapolated to infinity; $C_{\text {max }}$, maximum plasma concentration; $S E$, standard error.

followed by a $\leq 26$-day double-blind treatment phase, with adverse events evaluated during the trial and for an additional 30 days thereafter. A total of 130 patients (69 female, 61 male) were enrolled in the study, with a mean \pm SD age of $56 \pm 12$ years. Previous medications for BTCP consisted of oral opioids for $93.5 \%$ of patients. Thirty-two patients withdrew from the study during the titration phase, and three withdrew during the doubleblind phase. The most common reasons for withdrawal were patient decision $(n=16)$, adverse events $(n=7)$, and titration failure $(\mathrm{n}=3){ }^{29}$

Ninety-eight patients (75.4\%) were successfully titrated during the titration phase, and the median effective dose of fentanyl sublingual spray was $800 \mu \mathrm{g} .{ }^{29}$ The mean \pm standard error (SE) summed pain intensity difference score at 30 minutes after administration $\left(\operatorname{SPID}_{30}\right)$, the primary efficacy measure, was $640.3 \pm 47.8$ in patients receiving fentanyl sublingual spray compared with $399.6 \pm 40.8$ in patients receiving placebo $(P<0.0001) .{ }^{29}$ Fentanyl sublingual spray was significantly more effective than placebo in reducing pain intensity, as measured by mean pain intensity difference and SPID scores, from 5 minutes through 60 minutes, the last time period assessed ( $P<0.05$ for all time points) (Figure 5). The mean $\pm \mathrm{SE}$ total pain relief score at $30 \mathrm{~min}$ utes $\left(\right.$ TOTPAR $_{30}$ ), a secondary efficacy measure, was also significantly greater with fentanyl sublingual spray than with placebo $(78.3 \pm 2.1$ versus $61.0 \pm 2.2 ; P<0.0001)$.
Pain relief scores and TOTPAR scores were significantly higher with fentanyl sublingual spray than with placebo from 5 minutes through 60 minutes $(P<0.0001$ for all time points). ${ }^{29}$

Patient satisfaction was assessed using the Treatment Satisfaction Questionnaire for Medication (TSQM), a validated assessment tool. ${ }^{29,56,57}$ Treatment satisfaction on all four TSQM domains (effectiveness, side effects, convenience, overall satisfaction) improved from the start of the titration phase (baseline) to the double-blind treatment phase (Figure 6). ${ }^{29}$ Notably, of the 95 patients who completed the double-blind phase, 90 (94.7\%) chose to continue in an open-label extension phase of the trial. $^{29}$

Seventy-eight patients $(60.0 \%)$ reported adverse events during the titration phase, and $47(48.0 \%)$ reported adverse events during the double-blind phase. ${ }^{29}$ The most common adverse events were nausea $(\mathrm{n}=17)$, somnolence $(\mathrm{n}=11)$, dizziness $(\mathrm{n}=10)$, and vomiting $(\mathrm{n}=10)$ during the titration phase and nausea $(\mathrm{n}=7)$, hyperhidrosis $(\mathrm{n}=5)$, and peripheral edema $(\mathrm{n}=5)$ during the doubleblind phase. ${ }^{29}$ Adverse events considered to be probably related to treatment occurred in 33 subjects $(25.4 \%)$ in the titration phase and two subjects $(2.0 \%)$ in the doubleblind phase. ${ }^{29}$

The results of this clinical trial demonstrate the efficacy and tolerability of fentanyl sublingual spray for 


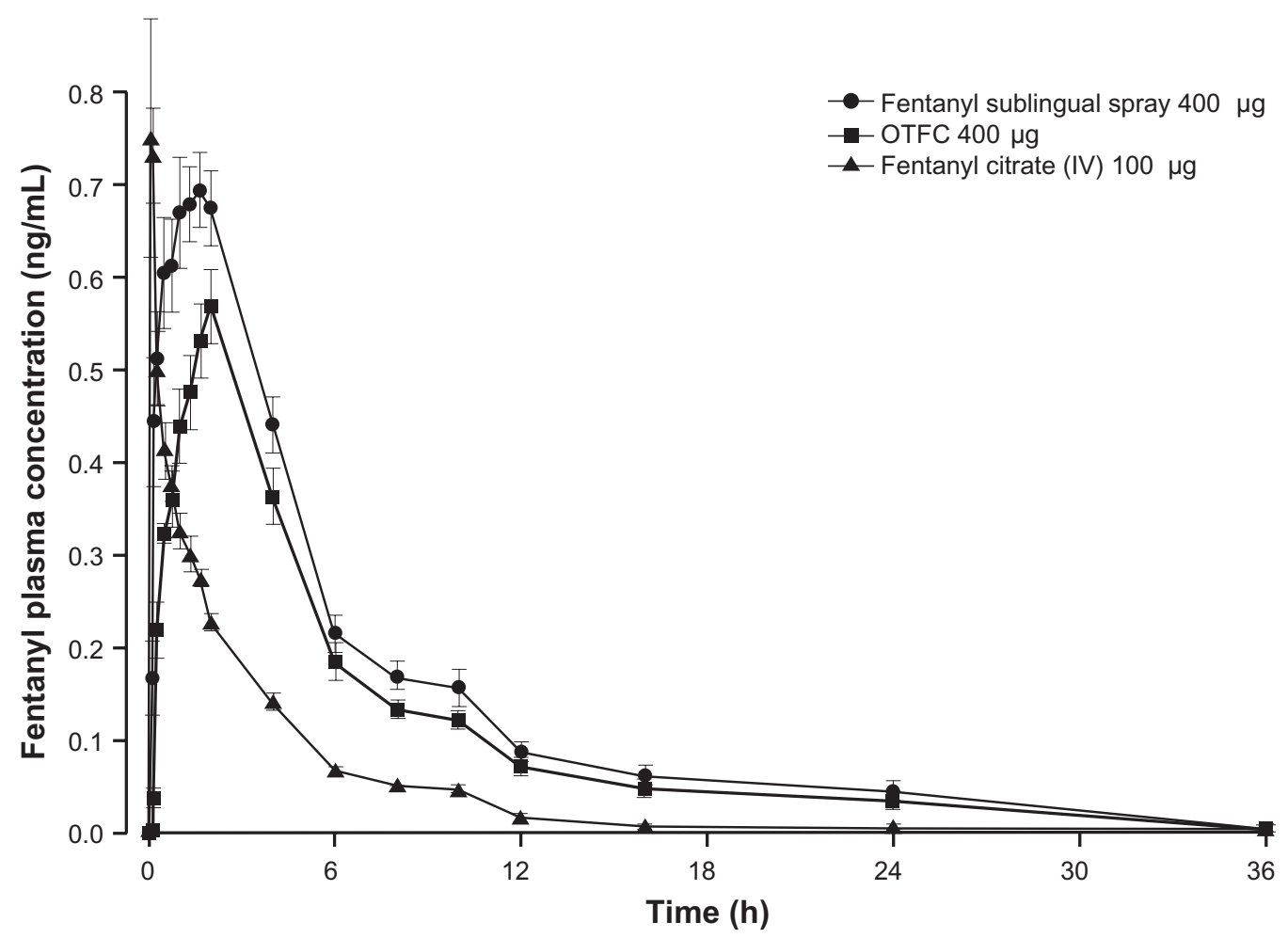

Figure 3 Mean \pm SE fentanyl plasma concentrations ( $\mathrm{ng} / \mathrm{mL}$ ) over time ( 5 minutes to 36 hours) after a single administration of fentanyl sublingual spray $400 \mu \mathrm{g}$, oral transmucosal fentanyl citrate $400 \mu \mathrm{g}$, or intravenous fentanyl citrate $100 \mu \mathrm{g}$ in healthy volunteers.

Notes: Reprinted from Clin Ther. Vol 35, Parikh N, Goskonda V, Chavan A, Dillaha L, Single-dose pharmacokinetics of fentanyl sublingual spray and oral transmucosal fentanyl citrate in healthy volunteers: a randomized crossover study, pages 236-243. Copyright @ 2013, with permission from Elsevier. ${ }^{36}$

Abbreviations: IV, intravenous; OTFC, oral transmucosal fentanyl citrate.

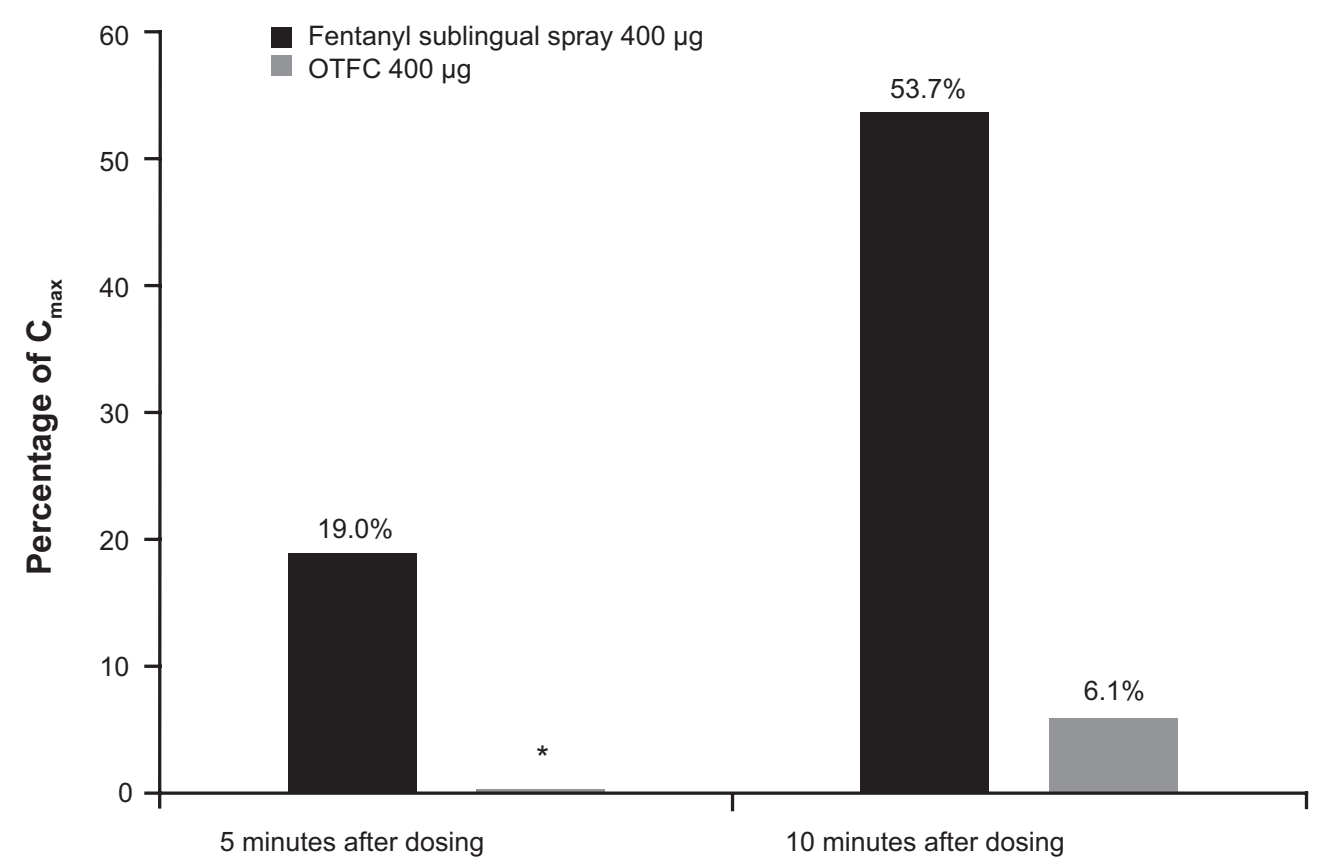

Figure 4 Plasma fentanyl concentrations, expressed as a percentage of $C_{\text {max }}$ at 5 and 10 minutes after a single administration of fentanyl sublingual spray (400 $\left.\mu \mathrm{g}\right)$ or oral transmucosal fentanyl citrate $(400 \mu \mathrm{g})$ in healthy volunteers.

Notes: *Below the lower limit of quantification. Reprinted from Clin Ther. Vol 35, Parikh N, Goskonda V, Chavan A, Dillaha L, Single-dose pharmacokinetics of fentanyl sublingual spray and oral transmucosal fentanyl citrate in healthy volunteers: a randomized crossover study, pages 236-243. Copyright ( 2013 , with permission from Elsevier. ${ }^{36}$

Abbreviations: $\mathrm{C}_{\max }$, maximum plasma concentration; OTFC, oral transmucosal fentanyl citrate. 

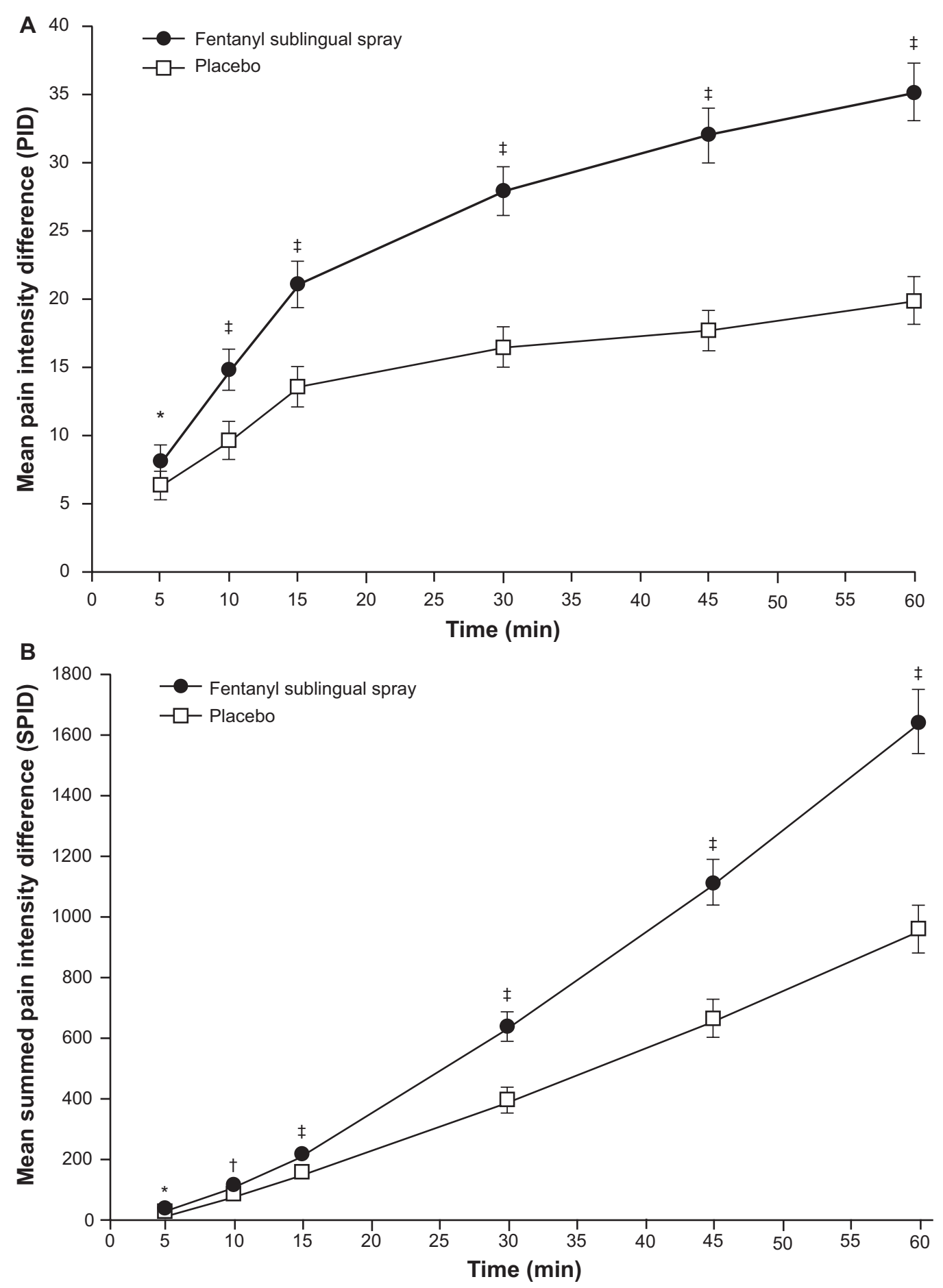

Figure 5 Mean \pm SE pain intensity difference (A) and mean summed pain intensity difference (B) scores over time (5-60 minutes) after administration of fentanyl sublingual spray or placebo in patients with breakthrough cancer pain.

Notes: $* P<0.05 ; \uparrow P<0.01$; $¥ P<0.000$ I. Rauck R, Reynolds L, Geach J, et al. Curr Med Res Opin. 2012;28(5):859-870. Copyright $\odot$ 20I2, Informa Healthcare. Reprinted with permission of Informa Healthcare. ${ }^{29}$

Abbreviation: SE, standard error.

the treatment of BTCP in opioid-tolerant adult patients. Fentanyl sublingual spray showed significant reduction in pain at 5 minutes after administration, with pain relief lasting at least 60 minutes, the last time point evaluated. Importantly, more than $75 \%$ of patients were successfully titrated from their prior BTCP medication to fentanyl sublingual spray, and nearly all were satisfied with treatment during the double-blind phase, as indicated by their opting to continue on therapy. Adverse events were generally mild to moderate. ${ }^{29}$ 


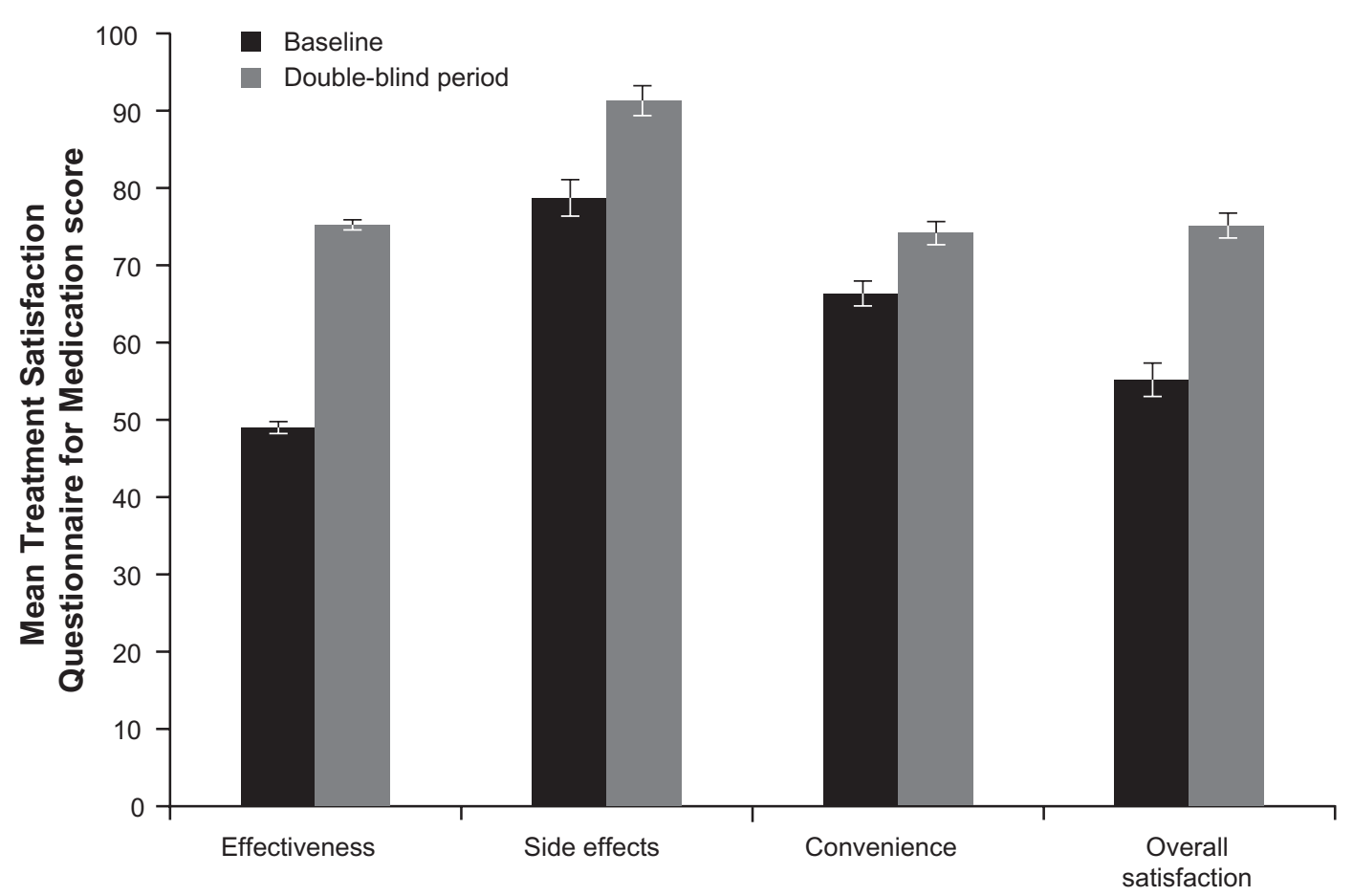

Figure 6 Mean \pm SE Treatment Satisfaction Questionnaire for Medication scores at baseline (ie, beginning of the titration period) and at the start of the double-blind treatment phase.

Notes: Higher scores indicate greater satisfaction with treatment. Rauck R, Reynolds L, Geach J, et al. Curr Med Res Opin. 20I2;28(5):859-870. Copyright (C 20I2, Informa Healthcare. Reprinted with permission of Informa Healthcare. ${ }^{29}$

Abbreviation: SE, standard error.

\section{Conclusion}

Effective management of BTCP episodes should be based on current knowledge of how quickly this exacerbation of pain can occur, with the goal of limiting its intensity and duration. Several rapid-onset formulations of fentanyl have demonstrated efficacy and tolerability in the treatment of BTCP in opioid-tolerant patients. Fentanyl sublingual spray, the newest of these products, has the characteristics of an ideal BTCP treatment - it has proven efficacy, rapid onset (with significant measurable effects within 5 minutes of administration), a relatively short duration of action, a tolerable adverse event profile, is easily administered, and may improve overall patient satisfaction with BTCP treatment.

\section{Acknowledgment}

Technical editorial and writing assistance was provided by Karamarie Fecho, $\mathrm{PhD}$, for Synchrony Medical Communications, LLC, West Chester, PA, USA. Funding for this support was provided by INSYS Therapeutics, Inc, Chandler, AZ, USA.

\section{Disclosure}

Dr Taylor discloses that he has participated on the speakers' bureau for INSYS Therapeutics, Inc. Dr Taylor has no other conflicts of interest to declare.

\section{References}

1. Kumar N. WHO Normative Guidelines on Pain Management. Report of a Delphi Study to determine the need for guidelines and to identify the number and topics of guidelines that should be developed by WHO. Geneva: World Health Organization; 2007. Available from: http://www. who.int/medicines/areas/quality_safety/delphi_study_pain_guidelines. pdf. Accessed April 18, 2013.

2. Margarit C, Juliá J, López R, et al. Breakthrough cancer pain - still a challenge. J Pain Res. 2012;5:559-566.

3. World Health Organization. Cancer Pain Relief: With a Guide to Opioid Availability, 2nd ed. Geneva: World Health Organization; 1996. Available from: http://whqlibdoc.who.int/publications/9241544821.pdf. Accessed April 18, 2013.

4. World Health Organization. WHO's Pain Ladder for Adults. Available from: http://www.who.int/cancer/palliative/painladder/en/. Accessed April 18, 2013.

5. Portenoy RK, Hagen NA. Breakthrough pain: definition, prevalence and characteristics. Pain. 1990;41(3):273-281.

6. Portenoy RK, Payne D, Jacobsen P. Breakthrough pain: characteristics and impact in patients with cancer pain. Pain. 1999;81(1-2): 129-134.

7. Zeppetella G, O’Doherty CA, Collins S. Prevalence and characteristics of breakthrough pain in cancer patients admitted to a hospice. J Pain Symptom Manage. 2000;20(2):87-92.

8. Burton B, Zeppetella G. Assessing the impact of breakthrough cancer pain. Br J Nurs. 2011;20(10):S14, S16-S19.

9. Dickman A. Integrated strategies for the successful management of breakthrough cancer pain. Curr Opin Support Palliat Care. 2011; $5(1): 8-14$

10. Elsner F, Zeppetella G, Porta-Sales J, Tagarro I. Newer generation fentanyl transmucosal products for breakthrough pain in opioid-tolerant cancer patients. Clin Drug Investig. 2011;31(9):605-618.

11. Nicholson B, Agarwala SS. Opioid delivery in the treatment of cancer breakthrough pain: a review of routes of administration. J Opioid Manag. 2011;7(1):69-79. 
12. Mercadante S. Pharmacotherapy for breakthrough cancer pain. Drugs. 2012;72(2):181-190.

13. Moore N, Darwish M, Amores X, Schneid H. A review of the pharmacokinetic profile of transmucosal fentanyl formulations. Curr Med Res Opin. 2012;28(11):1781-1790.

14. Zhang H, Zhang J, Streisand JB. Oral mucosal drug delivery: clinical pharmacokinetics and therapeutic applications. Clin Pharmacokinet. 2002;41(9):661-680.

15. Weinberg DS, Inturrisi CE, Reidenberg B, et al. Sublingual absorption of selected opioid analgesics. Clin Pharmacol Ther. 1988;44(3): 335-342.

16. Davis MP. Fentanyl for breakthrough pain: a systematic review. Expert Rev Neurother. 2011;11(8):1197-1216.

17. Mercadante S. Oral transmucosal fentanyl citrate for breakthrough pain treatment in cancer patients. Expert Opin Pharmacother. 2012;13(6):873-878.

18. Portenoy RK, Taylor D, Messina J, Tremmel L. A randomized, placebo-controlled study of fentanyl buccal tablet for breakthrough pain in opioid-treated patients with cancer. Clin J Pain. 2006;22(9): 805-811.

19. INSYS Therapeutics announces FDA approval of Subsys ${ }^{\circledR}$ fentanyl sublingual spray [press release]. Phoenix, AZ: INSYS Therapeutics, Inc; January 5, 2012. Available from: http://www.marketwire.com/ press-release/insys-therapeutics-announces-fda-approval-of-subsysrfentanyl-sublingual-spray-pinksheets-neol-1603533.htm. Accessed April 18, 2013.

20. Actiq $^{\circledR}$ (fentanyl citrate) oral transmucosal lozenge, CII [package insert]. Frazer, PA: Cephalon, Inc; 2011.

21. Abstral ${ }^{\circledR}$ (fentanyl) sublingual tablets, CII [package insert]. Bridgewater, NJ: ProStrakan, Inc; 2012.

22. Fentora ${ }^{\circledR}$ (fentanyl citrate) buccal tablet, CII [package insert]. North Wales, PA: Teva Pharmaceuticals USA, Inc; 2013.

23. Onsolis ${ }^{\circledR}$ (fentanyl buccal soluble film), CII [package insert]. Somerset, NJ: Meda Pharmaceuticals Inc; 2011.

24. Lazanda ${ }^{\circledR}$ (fentanyl) nasal spray, CII [package insert]. Bedminster, NJ: Archimedes Pharma US, Inc; 2012.

25. Subsys ${ }^{\circledR}$ (fentanyl sublingual spray), CII [package insert]. Chandler, AZ: INSYS Therapeutics, Inc; 2012.

26. Rauck RL, Tark M, Reyes E, et al. Efficacy and long-term tolerability of sublingual fentanyl orally disintegrating tablet in the treatment of breakthrough cancer pain. Curr Med Res Opin. 2009;25(12): $2877-2885$.

27. Rauck R, North J, Gever LN, Tagarro I, Finn AL. Fentanyl buccal soluble film (FBSF) for breakthrough pain in patients with cancer: a randomized, double-blind, placebo-controlled study. Ann Oncol. 2010;21(6):1308-1314.

28. Portenoy RK, Burton AW, Gabrail N, Taylor D; Fentanyl Pectin Nasal Spray 043 Study Group. A multicenter, placebo-controlled, double-blind, multiple-crossover study of Fentanyl Pectin Nasal Spray (FPNS) in the treatment of breakthrough cancer pain. Pain. 2010;151(3):617-624.

29. Rauck R, Reynolds L, Geach J, et al. Efficacy and safety of fentanyl sublingual spray for the treatment of breakthrough cancer pain: a randomized, double-blind, placebo-controlled study. Curr Med Res Opin. 2012;28(5):859-870.

30. Farrar JT, Cleary J, Rauck R, Busch M, Nordbrock E. Oral transmucosal fentanyl citrate: randomized, double-blinded, placebo-controlled trial for treatment of breakthrough pain in cancer patients. $J$ Natl Cancer Inst. 1998;90(8):611-616.

31. Taylor D, Galan V, Weinstein SM, Reyes E, Pupo-Araya AR, Rauck R; Fentanyl Pectin Nasal Spray 043 Study Group. Fentanyl pectin nasal spray in breakthrough cancer pain. J Support Oncol. 2010;8(4): 184-190.

32. Wynn RL. The sugar-loaded fentanyl lollipop (Actiq) and the risk for tooth decay. Gen Dent. 2011;59(3):168-170.

33. Hansen MS, Mathiesen O, Trautner S, Dahl JB. Intranasal fentanyl in the treatment of acute pain - a systematic review. Acta Anaesthesiol Scand. 2012;56(4):407-419.
34. Walker G, Wilcock A, Manderson C, Weller R, Crosby V. The acceptability of different routes of administration of analgesia for breakthrough pain. Palliat Med. 2003;17(2):219-221.

35. Davies AN. The management of breakthrough cancer pain. Br J Nurs. 2011;20(13):803-804, 806-807.

36. Parikh N, Goskonda V, Chavan A, Dillaha L. Single-dose pharmacokinetics of fentanyl sublingual spray and oral transmucosal fentanyl citrate in healthy volunteers: a randomized crossover study. Clin Ther. 2013;35(3):236-243.

37. Swarm R, Abernethy AP, Anghelescu DL, et al; NCCN Adult Cancer Pain. Adult cancer pain. J Natl Compr Canc Netw. 2010;8(9):1046-1086.

38. Ripamonti CI, Bandieri E, Roila F; ESMO Guidelines Working Group. Management of cancer pain: ESMO Clinical Practice Guidelines. Ann Oncol. 2011;22(Suppl 6):vi69-vi77.

39. Caraceni A, Hanks G, Kaasa S, et al; European Palliative Care Research Collaborative (EPCRC); European Association for Palliative Care (EAPC). Use of opioid analgesics in the treatment of cancer pain: evidence-based recommendations from the EAPC. Lancet Oncol. 2012;13(2):e58-e68.

40. Davies AN, Dickman A, Reid C, Stevens AM, Zeppetella G; Science Committee of the Association for Palliative Medicine of Great Britain and Ireland. The management of cancer-related breakthrough pain: recommendations of a task group of the Science Committee of the Association for Palliative Medicine of Great Britain and Ireland. Eur J Pain. 2009;13(4):331-338.

41. Nalamachu SR, Narayana A, Janka L. Long-term dosing, safety, and tolerability of fentanyl buccal tablet in the management of noncancerrelated breakthrough pain in opioid-tolerant patients. Curr Med Res Opin. 2011;27(4):751-760.

42. Fine PG, Messina J, Xie F, Rathmell J. Long-term safety and tolerability of fentanyl buccal tablet for the treatment of breakthrough pain in opioid-tolerant patients with chronic pain: an 18-month study. $J$ Pain Symptom Manage. 2010;40(5):747-760.

43. Passik SD, Messina J, Golsorkhi A, Xie F. Aberrant drug-related behavior observed during clinical studies involving patients taking chronic opioid therapy for persistent pain and fentanyl buccal tablet for breakthrough pain. J Pain Symptom Manage. 2011;41(1):116-125.

44. Koyyalagunta D, Bruera E, Solanki D, et al. A systematic review of randomized trials on the effectiveness of opioids for cancer pain. Pain Physician. 2012;15:ES39-ES58.

45. Francoeur RB. Ensuring safe access to medication for palliative care while preventing prescription drug abuse: innovations for American inner cities, rural areas, and communities overwhelmed by addiction. Risk Manag Healthcare Policy. 2011;4:97-105.

46. US Food and Drug Administration. Transmucosal immediate release fentanyl (TIRF) Risk Evaluation and Mitigation Strategy (REMS). Available from: http://www.fda.gov/downloads/Drugs/DrugSafety/ PostmarketDrugSafetyInformationforPatientsandProviders/ UCM289730.pdf. Updated June 20, 2012. Accessed May 21, 2013.

47. US Food and Drug Administration. Extended-release (ER) and longacting (LA) opioid analgesics Risk Evaluation and Mitigation Strategy (REMS). Available from: http://www.fda.gov/downloads/Drugs/ DrugSafety/PostmarketDrugSafetyInformationforPatientsandProvide rs/UCM311290.pdf. Updated April 2013. Accessed May 21, 2013.

48. Shojaei AH. Buccal mucosa as a route for systemic drug delivery: a review. J Pharm Pharm Sci. 1998;1(1):15-30.

49. Harris D, Robinson JR. Drug delivery via the mucous membranes of the oral cavity. J Pharm Sci. 1992;81(1):1-10.

50. Malkawi AH, Al-Ghananeem AM, Crooks PA. Development of a GC-MS assay for the determination of fentanyl pharmacokinetics in rabbit plasma after sublingual spray delivery. AAPS J. 2008;10(2):261-267.

51. Pather I, Siebert JM, Hontz J, Khankari R, Kumbale R, Gupte S. Enhanced buccal delivery of fentanyl using the OraVescent drug delivery system. Drug Delivery Technol. 2001;1(1):54-57.

52. Coutel-Egros A, Maitani Y, Veillard M, Machida Y, Nagai T. Combined effects of $\mathrm{pH}$, cosolvent and penetration enhancers on the in vitro buccal absorption of propranolol through excised hamster cheek pouch. Int $J$ Pharm. 1992;84(2):117-128. 
53. Kitano M, Maitani Y, Takayama K, Nagai T. Buccal absorption through golden hamster cheek pouch in vitro and in vivo of $17 \beta$-estradiol from hydrogels containing three types of absorption enhancers. Int J Pharm. 1998;174(1):19-28.

54. Shojaei AH, Khan M, Lim G, Khosravan R. Transbuccal permeation of a nucleoside analog, dideoxycytidine: effects of menthol as a permeation enhancer. Int J Pharm. 1999;192(2):139-146.

55. Parikh N, Goskonda V, Chavan A, Dillaha L. Pharmacokinetics and dose proportionality of fentanyl sublingual spray: a single-dose 5-way crossover study. Clin Drug Investig. 2013;33(6):391-400.
56. Atkinson MJ, Sinha A, Hass SL, et al. Validation of a general measure of treatment satisfaction, the Treatment Satisfaction Questionnaire for Medication (TSQM), using a national panel study of chronic disease. Health Qual Life Outcomes. 2004;2:12.

57. Atkinson MJ, Kumar R, Cappelleri JC, Hass SL. Hierarchical construct validity of the Treatment Satisfaction Questionnaire for Medication (TSQM version II) among outpatient pharmacy consumers. Value Health. 2005;8(Suppl 1):S9-S24.

\section{Publish your work in this journal}

Clinical Pharmacology: Advances and Applications is an international, peer-reviewed, open access journal publishing original research, reports, reviews and commentaries on all areas of drug experience in humans The manuscript management system is completely online and includes a very quick and fair peer-review system, which is all easy to use.
Visit http://www.dovepress.com/testimonials.php to read real quotes from published authors.

Submit your manuscript here: http://www.dovepress.com/clinical-pharmacology-advances-and-applications-journal 